\title{
The genetics of bicuspid aortic valve disease: Shall we take it down a NOTCH?
}

\author{
Leora B. Balsam, MD
}

\author{
From the Division of Cardiac Surgery, UMass Memorial Medical Center, Worcester, Mass. \\ Disclosures: Author has nothing to disclose with regard to commercial support. \\ Received for publication Feb 20, 2018; accepted for publication Feb 23, 2018; available ahead of print March 20, \\ 2018. \\ Address for reprints: Leora B. Balsam, MD, Division of Cardiac Surgery, UMass Memorial Medical Center, Uni- \\ versity Campus, 55 Lake Ave N, Worcester, MA 01655 (E-mail: leora.balsam@umassmemorial.org). \\ J Thorac Cardiovasc Surg 2018;156:523-4 \\ $0022-5223 / \$ 36.00$ \\ Copyright (C) 2018 by The American Association for Thoracic Surgery \\ https://doi.org/10.1016/j.jtcvs.2018.02.051
}

Bicuspid aortic valve (BAV) disease is a common disorder, affecting $1 \%$ to $2 \%$ of the population. It can occur in conjunction with other congenital heart defects or as an isolated lesion in nonsyndromic cases. Surgeons are familiar with the heterogeneity of BAV disease, which includes several valve morphologies, different propensities and modes of valvular degeneration, and a predisposition toward proximal thoracic aortic aneurysms.

The genetic basis of nonsyndromic BAV disease has been supported by genetic linkage studies, in which BAV disease segregates in an autosomal dominant pattern with incomplete penetrance. Garg and coworkers ${ }^{1}$ reported the association between loss of function mutations in the NOTCH1 gene in 2 different families with nonsyndromic BAV disease, and a follow-up study by Mohamed and associates ${ }^{2}$ implicated NOTCH1 gene mutations in $4 \%$ of sporadic BAV cases as well. McKellar and coworkers ${ }^{3}$ also found NOTCH1 gene variants in $10 \%$ of patients with concomitant BAV and thoracic aortic aneurysms, compared with $2.1 \%$ in control subjects. The NOTCH1 gene encodes a transmembrane receptor that is involved in cell fate determination and morphogenesis of the cardiac chambers and valves. ${ }^{4}$ It promotes epithelial to mesenchymal transition during valvulogenesis, and in the adult it is involved in valvular and vascular homeostasis. On ligand binding, cleavage of the NOTCH1 receptor releases the protein's intracellular domain, which then translocates to the nucleus and triggers gene transcription. The low frequency of NOTCH1 mutations in the population with BAV disease suggests that NOTCHI is part, but not all, of the mechanistic story behind BAV development.

In this issue of the Journal, Jiao and colleagues ${ }^{5}$ reevaluate the contribution of $\mathrm{NOTCH}$ lo the pathogenesis of BAV disease, albeit from a different angle. They are specifically interested in the aortopathy associated with BAV disease, which preferentially involves the proximal thoracic aorta and leads to aneurysm and increased risk of dissection. They focus on the differentiation potential of precursor cells that populate the proximal thoracic aorta and the effect of

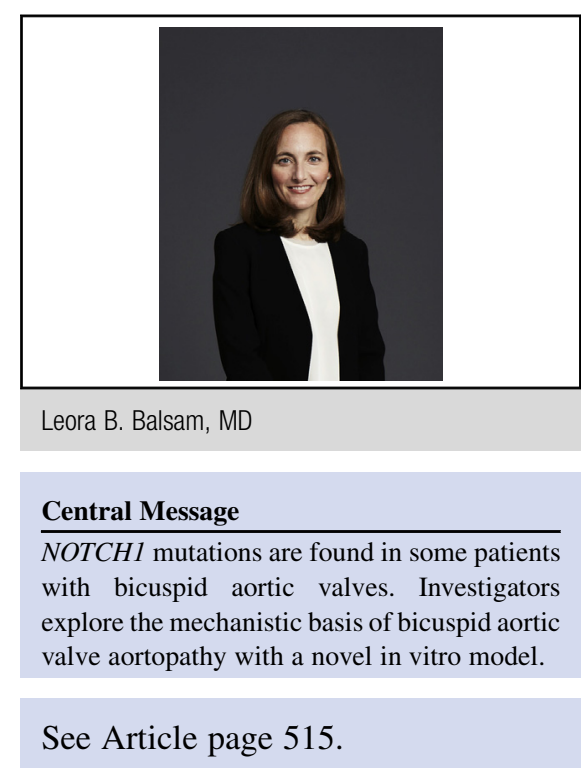

NOTCH1 loss of function on this process. Their hypothesis is that loss of NOTCHI function will impair cellular differentiation, and in vivo, this could result in an aortopathy. Rather than focus on the organism as a whole, however, they take a microscopic view and use advanced techniques in stem cell biology and gene editing to answer their questions. Their model consists of in vitro induced pluripotent stem cells derived from peripheral blood mononuclear cells of a single donor with a normal trileaflet aortic valve. Jiao and colleagues ${ }^{5}$ use CRISPR/Cas 9 gene editing to generate iPSCs with NOTCH1 loss of function. With this model, Jiao and colleagues ${ }^{5}$ find impaired differentiation of NOTCHI loss of function iPSCs along 2 pathways: (1) iPSC to neural crest stem cell to smooth muscle cell and (2) iPSC to cardiovascular progenitor cell to endothelial cell. They conclude that NOTCHI is likely a key factor in the differentiation of proximal aortic smooth muscle cells and endothelial cells from their stem cell precursors.

This study is an interesting extension of the previous work of Jiao and colleagues, ${ }^{6}$ which also used an iPSC model to identify defects in differentiation and function of smooth muscle cells from patients with BAVs and thoracic aortic aneurysms. ${ }^{6}$ They identified abnormalities in the differentiation pathway from iPSC to neural crest stem cell to smooth muscle cell, which models characteristics in the proximal aorta. In contrast, the differentiation pathway from iPSC to paraxial mesoderm cell to smooth muscle cell (which models characteristics in the descending aorta) 
was not affected. These in vitro studies support the hypothesis that smooth muscle cell phenotypes of the proximal (as opposed to descending) aorta behave abnormally in patients with BAVs and thoracic aortic aneurysms versus those in control patients with tricuspid aortic valves.

The study of Jiao and colleagues ${ }^{5}$ has refocused attention on $\mathrm{NOTCH} 1$ as a genetic regulator of $\mathrm{BAV}$, providing mechanistic insights into how defective $\mathrm{NOTCH} 1$ signaling may lead to aortopathy. But is this where we should be looking? In trying to support this direction of research, Jiao and colleagues ${ }^{5}$ examined a panel of 108 patients with BAVs, and they found no missense or nonsense mutations in NOTCH1. This finding points to the reality that $\mathrm{NOTCHI}$ is at best a supporting actor in the aortopathy of BAV disease, and the leading actors remain unknown.

\section{References}

1. Garg V, Muth AN, Ransom JF, Schluterman MK, Barnes R, King IN, et al. Mutations in NOTCH1 cause aortic valve disease. Nature. 2005;437:270-4.

2. Mohamed SA, Aherrahrou Z, Liptau H, Erasmi AW, Hagemann C, Wrobel S, et al. Novel missense mutations (p.T596M and p.P1797H) in NOTCH1 in patients with bicuspid aortic valve. Biochem Biophys Res Commun. 2006;345: 1460-5.

3. McKellar SH, Tester DJ, Yagubyan M, Majumdar R, Ackerman MJ, Sundt TM. Novel NOTCH1 mutations in patients with bicuspid aortic valve disease and thoracic aortic aneurysms. J Thorac Cardiovasc Surg. 2007;134:290-6.

4. MacGrogan D, Luna-Zurita L, de la Pompa JL. Notch signaling in cardiac valve development and disease. Birth Defects Res A Clin Mol Teratol. 2011;91:449-59.

5. Jiao J, Tian W, Qui P, Norton EL, Wang MM, Chen YE, et al. Induced pluripotent stem cells with NOTCH1 gene mutation show impaired differentiation into smooth muscle and endothelial cells: implications for bicuspid aortic valverelated aortopathy. J Thorac Cardiovasc Surg. 2018;156:515-22.

6. Jiao J, Xiong W, Wang L, Yang J, Qiu P, Hirai H, et al. Differentiation defect in neural crest-derived smooth muscle cells in patients with aortopathy associated with bicuspid aortic valves. EBioMedicine. 2016;10:282-90. 